\title{
Numerical Simulation of Gas-solid Flow and Pulverized Coal Combustion in a Swirl Chamber Precalciner
}

\author{
Xiaolin Chen ${ }^{1, a}$, Junlin Xie ${ }^{1, b *}$, Shuxia Mei ${ }^{1, c}$,Shasha Shen ${ }^{1, d}$ \\ ${ }^{1}$ State Key Laboratory of Silicate Materials for Architectures, Wuhan University of Technology, \\ Wuhan 430070, China

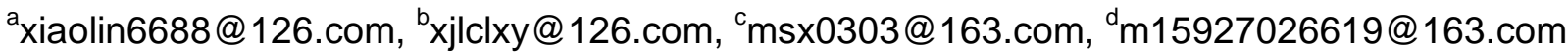

\begin{abstract}
Keywords:Precalciner; swirl chamber; coal combustion; decomposition; numerical simulation
Abstract. Efficient mixing of pulverized coal and calcium carbonate particles inside precalciner is important due to the reason that the mix process directly affects the final coal burn-out ratio and calcium carbonate decomposition ratio. The focus of this paper is on the gas-solid flow and pulverized coal combustion in an in-line swirl chamber precalciner. In terms of commercial computational fluid dynamics (CFD) code, the gas-solid flow characteristics, the temperature distribution and components distribution were obtained by numerical simulation of a 5000t/d swirl chamber precalciner. The results of simulation showed the characteristics of gas-solid flow that the gas rised spirally after being injected into the precalciner, the velocity in the center was lower, and the particles moved with gas-flow. The combustion of pulverized coal was mainly right in the upper of the swirl chamber and above the swirl chamber. The decomposition of calcium carbonate was also in the swirl chamber and the middle and lower part of the precalciner. The predicted coal burn-out ratio was about $100 \%$, and the predicted calcium carbonate decomposition ratio was $96.14 \%$. The results were in good agreement with actual measurement and can be used for further study to structure optimization design of precalciner.
\end{abstract}

\section{Introduction}

The precalciner used in the cement industry is a large-scale and complex reactor in chemical engineering. As high-temperature gas-solid reactor, the function of precalciner are gas-solid dispersion, pulverized coal combustion and calcium carbonate decomposition ${ }^{[1-3]}$. It is significance to study the characteristics of gas-solid flow, and the distribution of temperature and components. It can account for the thermal enthalpy of pulverized coal combustion and calcium carbonate decomposition, which is a benefit to study the structure optimization design of precalciner.

The conventional method of predicting the flow field and the temperature distribution is empirical. In the past several decades, application of CFD for the numerical simulation of the flow field and solid trajectories becomes more and more popular.

Wang, B obtained the gas-solid flow in a cyclone separator by the use of the Reynolds stress model and predicted some factors affected the separation efficiency and pressure drop in the cyclone ${ }^{[4]}$. D. K. Fidaros calculated trajectories of particles and their interaction with gas phase and explained the flow and transport phenomena in the precalciner ${ }^{[5]}$. D.Giddings investigated the performance of a precalciner, and represented the reactions and fluid dynamics ${ }^{[6]}$. Mikulč ić $\mathrm{H}$ studied the mechanism of calcium carbonate decomposition and concentrations of reactants and products ${ }^{[7-8]}$.

Their experiment methods are meaningful for analysis of precalciner. However, the study on the structure of the precalciner with swirl chamber is rare. And the characteristics of gas-solid flow, and the distribution of temperature and components in the swirl chamber precalciner are not clear.

Given those factors, this paper shall focus both analytically and numerically on the following topics based on a 5000t/d in-line swirl chamber precalciner: (1) the streamline of gas-flow and particles trajectory; (2) the temperature distributions in two different kinds of conditions, one is single pulverized coal combustion, the other is the coupling of pulverized coal combustion and $\mathrm{CaCO}_{3}$ decomposition; (3) the components distribution in the condition of $\mathrm{CaCO}_{3}$ decomposition; (4) the effect of $\mathrm{CaCO}_{3}$ decomposition to the pulverized coal combustion. 


\section{Geometrical model and mathematical model}

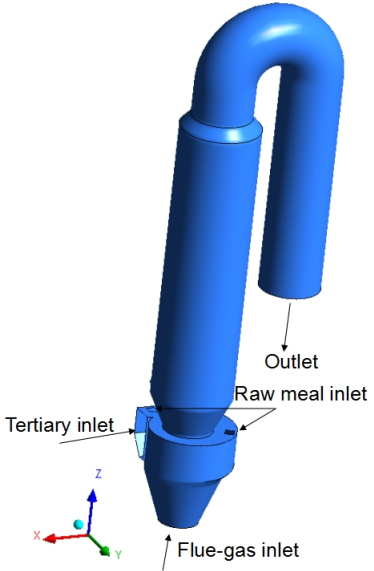

Fig. 1. Schematic view of the swirl chamber precalciner.

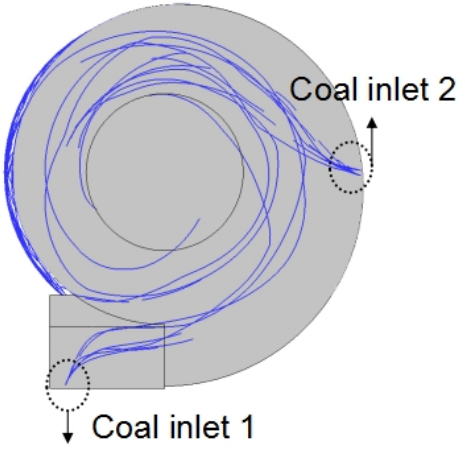

Fig. 2. Schematic diagram of coal inlets.

Fig. 1 shows the schematic view of the precalciner with swirl chamber. Hexahedral cell is used to mesh the whole precalciner and grid refinement is adopted in the swirl chamber. The flue-gas enters into the precalciner from the bottom, the tertiary air inlet is at the side of the body and the tertiary air enters into the swirl chamber in tangent direction. The tertiary air inlet is set at the bottom of the precalciner, which combined with the flue-gas to enhance the mixing effect of materials. The swirl chamber can effectively prolong the residence time of fluids. The raw meal inlets are right above the swirl chamber. The pulverized coal were injected into the precalciner horizontally at the height of $\mathrm{z}=0 \mathrm{~m}$. Fig. 2 shows the schematic diagram of the pulverized coal inlets. The two pulverized coal inlets are exactly vertical, above the swirl chamber. The gooseneck structure can enhance the spouting effect and promote coal combustion and calcium carbonate decomposition.

In addition to the bottom of the flue-gas inlet, the tertiary air inlet, the top outlet, other parts are regarded as the wall and use standard wall functions to simulate that part.

In Euler coordinate system, the gas phase was expressed with the realizable k- $\varepsilon$ two equation model. Because the realizable k- $\varepsilon$ model have been provided the best performance of separated flows and flows with complex secondary flow features. The chemical reactions of combustion and decomposition were expressed with species transport model. In Lagrange coordinate system, the solid phase was expressed with the discrete phase model (DPM). The physical model is two-way turbulence coupling, which can enable the effect of change in turbulent quantities due to particle damping and turbulence eddies. Coal particles following the Rossin-Rammler size distribution are tracked using stochastic trajectories model and gravity effect is taken into account. Devolatilization model is single rate model, which assumes that the rate of devolatilization is first-order dependent on the amount of volatiles remaining in the particle.

Tab.1. Industrial analysis and elemental analysis of the pulverized coal.

\begin{tabular}{lllllllll}
\hline \multicolumn{2}{l}{ Proximate analysis/wt\% } & \multicolumn{3}{c}{ Mass fraction/wt\% } & \multicolumn{2}{c}{$\mathrm{Q}_{\text {net,daf }} / \mathrm{MJ} . \mathrm{kg}-1$} \\
\hline $\mathrm{M}_{\mathrm{ad}}$ & $\mathrm{FC}_{\mathrm{ad}}$ & $\mathrm{V}_{\mathrm{ad}}$ & $\mathrm{A}_{\mathrm{ad}}$ & $\mathrm{C}_{\mathrm{daf}}$ & $\mathrm{H}_{\mathrm{daf}}$ & $\mathrm{O}_{\mathrm{daf}}$ & $\mathrm{N}_{\mathrm{daf}}$ & \\
\hline 0.27 & 0.50 & 0.02 & 0.21 & 0.90 & 0.04 & 0.03 & 0.03 & 26.4 \\
\hline
\end{tabular}

All the parameters are given according to the in line 5000t/d swirl chamber precalciner. The height is about $50 \mathrm{~m}$, and diameter is $7.5 \mathrm{~m}$. All the inlets are velocity inlets- the velocity specification method is magnitude, normal to boundary; the turbulence specification method is intensity and hydraulic diameter. The outlet is pressure outlet. And the mass fluxes of both gas and solids are assumed at continuous. The whole wall is standard wall function. Table 1 shows the technical analysis index, elemental analysis index, and calorific value of the pulverized coal. 


\section{Results and discussion}

The streamline of gas-flow and particles trajectory

In the precalciner, the pulverized coal combustion and the $\mathrm{CaCO}_{3}$ decomposition are existence simultaneously. During the reaction process, pulverized coal particles and $\mathrm{CaCO}_{3}$ particles and gas flows interact strongly. The high fineness of the raw meals and the good turbulent mixing caused uniform and fast pulverized coal combustion and $\mathrm{CaCO}_{3}$ decomposition. Therefore, the fundamental question for analyzing the pulverized coal combustion and the $\mathrm{CaCO}_{3}$ decomposition is to analyze the gas-flow distribution and solid particles trajectory.

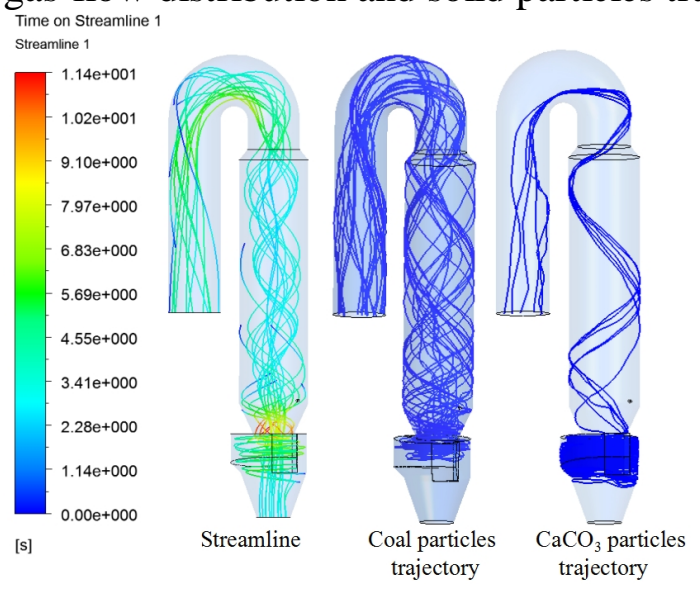

Fig.3. Gas-flow streamlines (a) and pulverized coal particles trajectory (b) and $\mathrm{CaCO}_{3}$ particles trajectory (c).
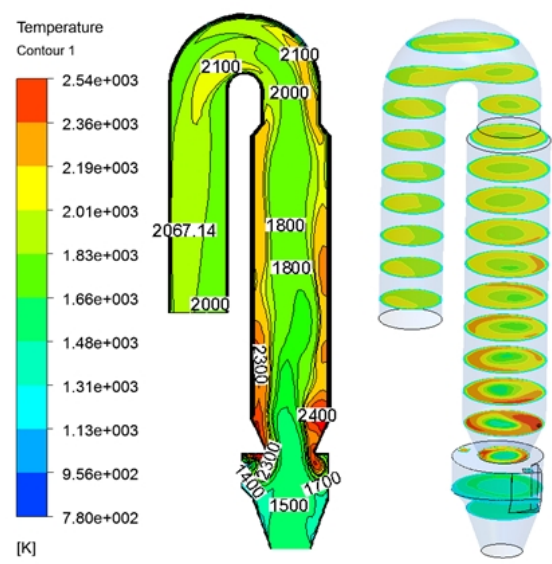

Fig.4. Temperature contours of pulverized coal combustion.
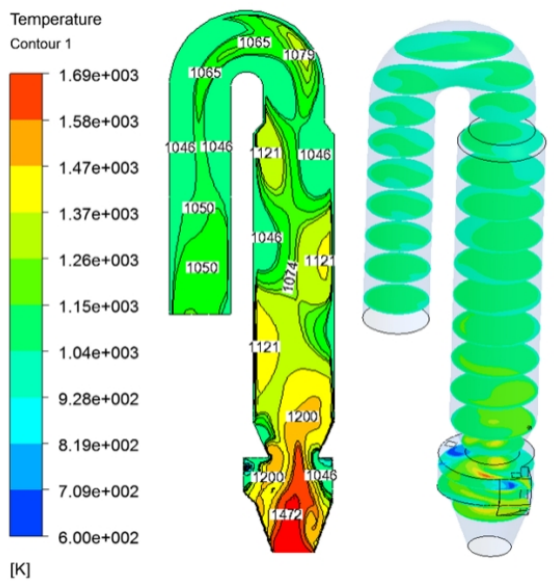

Fig.5. Temperature contours of pulverized coal combustion and $\mathrm{CaCO}_{3}$ decomposition.

Fig.3 shows the streamlines of gas-flow in precalciner (a), pulverized coal particles trajectory (b) and $\mathrm{CaCO}_{3}$ particles trajectory (c). The streamlines of gas-flow in the precalciner has multiple functions, which can provide oxygen to support combustion and transport particles ${ }^{[9]}$. Fig.3 (a) shows that the gas-flow rised spirally after being injected into the precalciner. And the circular streamline is at large scale in the swirl chamber. The streamlines in the central of the precaliciner are sparse. This kind of movement of rising spirally shows that the precalciner has a good overall vortex effect, which can prolong the residence time of raw materials, to enhance the dispersion effect of raw materials and coal in the precalciner. The average residence time is about 6s. It's long enough for the heat transfer of combustion and decomposition. Fig.3 (b) shows that the pulverized coal particles move with the gas-flow. The pulverized coal particles are dense in the swirl chamber and the diverging pipe and the residence time is quite long in this part. In the main body of the precalciner the inner diameter is bigger and the pulverized coal particles trajectories have high degree of bending. In the link of the main body 
of precalciner and gooseneck, the bending degree of the pulverized coal particles trajectories increase gradually with the decrease of the inside diameter. It is useful for the reaction of the unreacted particles. In the outlet part the pulverized coal particles trajectory is steady. Fig.3 (c) shows that the $\mathrm{CaCO}_{3}$ particles mainly distribute in the swirl chamber, a small quantity of $\mathrm{CaCO}_{3}$ particles move to the lower part of the swirl chamber, and part of $\mathrm{CaCO}_{3}$ particles move upwards with gas-flow. Compared with the movement of $\mathrm{CaCO}_{3}$ particles and pulverized coal particles, there is no large scale of $\mathrm{CaCO}_{3}$ particles rotational trajectory as pulverized coal particles. This is because the $\mathrm{CaCO}_{3}$ particles are injected into the precalciner vertically right above the swirl chamber, which interacts with the smoke moved upward. The ability to move upwards for $\mathrm{CaCO}_{3}$ particles is weak relatively. In general, the gas-flow streamlines and the pulverized coal particles are uniformly distributed in the body of precalciner, while the $\mathrm{CaCO}_{3}$ particles are not.

Temperature distribution in single pulverized coal combustion and $\mathrm{CaCO}_{3}$ decomposition

Fig.4 shows the temperature contours of the pulverized coal combustion at the cross section of $\mathrm{y}=0 \mathrm{~m}$ and the cross sections of temperature contours at different heights. It shows that the pulverized coal combusted quickly after being injected into precalciner. And the temperature is about $2300 \mathrm{k}$ in this region. The pulverized coal rises spirally with the movement of gas flow. The temperature in the center of the precalciner is lower, about 1800k. And the high-temperature zone becomes smaller gradually since the connection part of gooseneck and main body of the precalciner.The temperature is evenly distributed in the outlet part, about 2000k. With the post-processing of the numerical simulation gets that the density of volatiles, char and $\mathrm{CO}$ are about zero, that is to say, the pulverized coal burn-out ratio is about $100 \%$, which is in good agreement with the actual measurement.

In general, the upper swirl chamber is local high-temperature zone. Because the volatiles burn rapidly after the pulverized coal being injected into the precalciner. There exists a small high-temperature zone in this part. The temperature in the lower swirl chamber is lower and materials mainly mix and disperse in this part. The pulverized coal can burn further in the diverging pipe.

Combined the temperature contour of $\mathrm{y}=0 \mathrm{~m}$ and the temperature contours at different heights, it can find that the high-temperature zone dispersed spirally and the temperature in the center of the precalciner is lower, these are in agreement with the streamline of gas-flow. The high-temperature zone is mainly in the main body of the precalciner, materials can react efficiently with high temperature.

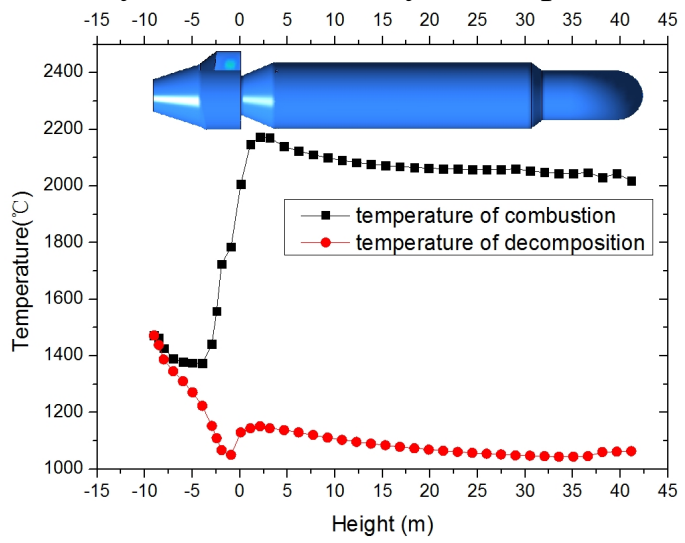

Fig.6. Average temperature curves of pulverized coal combustion and $\mathrm{CaCO}_{3}$ decomposition on cross slices along $\mathrm{z}$ direction.

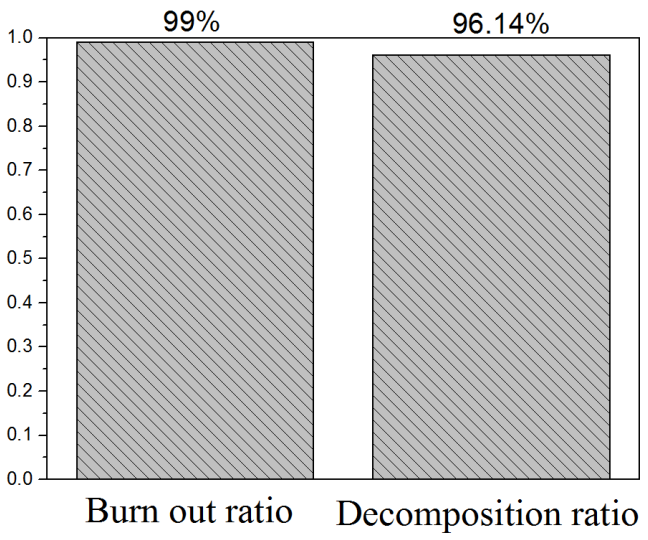

Fig.7. Pulverized coal burn-out ratio and $\mathrm{CaCO}_{3}$ decomposition ratio.

Fig. 5 shows the temperature contours of $\mathrm{CaCO}_{3}$ decomposition at the cross section of $\mathrm{y}=0 \mathrm{~m}$ and the cross sections of temperature contours at different heights. It shows that the high temperature zone rised spirally. The high temperature zone mainly distributed in the middle and lower segments of the precalciner. And the average temperature is about 1200k in this region. The temperature value in the connection part of gooseneck and main body of the precalciner is slightly higher. That' $\mathrm{s}$ because the spouting effect formed with the decreased inner diameter. And the pulverized coal may burn further. There is no highly raised temperature in this region because the endothermic reaction of $\mathrm{CaCO}_{3}$ decomposition. In general, in the coupling of pulverized coal combustion and $\mathrm{CaCO}_{3}$ decomposition, 
the low temperature is high enough for $\mathrm{CaCO}_{3}$ decomposition and can extend the lifetime of the firebricks. Fig. 6 shows the average temperature curves of pulverized coal combustion and $\mathrm{CaCO}_{3}$ decomposition on cross slices along $\mathrm{z}$ direction. It shows that the average temperature variation is high at the height of $-5 \mathrm{~m}<\mathrm{Z}<5 \mathrm{~m}$. And when the $\mathrm{CaCO}_{3}$ are injected into the precalciner, the average temperature has remarkable fall. It shows obviously that the energy from pulverized coal combustion is absorbed by $\mathrm{CaCO}_{3}$ decomposition. The average temperatures are both evenly distributed in the outlet part in the condition of combustion and decomposition. The simulation shows the decomposition rate of $\mathrm{CaCO}_{3}$ is $96.14 \%$, which is approximately equal to the actual decomposition rate of $\mathrm{CaCO}_{3}, 95 \%$. It is in good agreement with the actual measurement.

Component concentration of combustion and decomposition coupling reaction

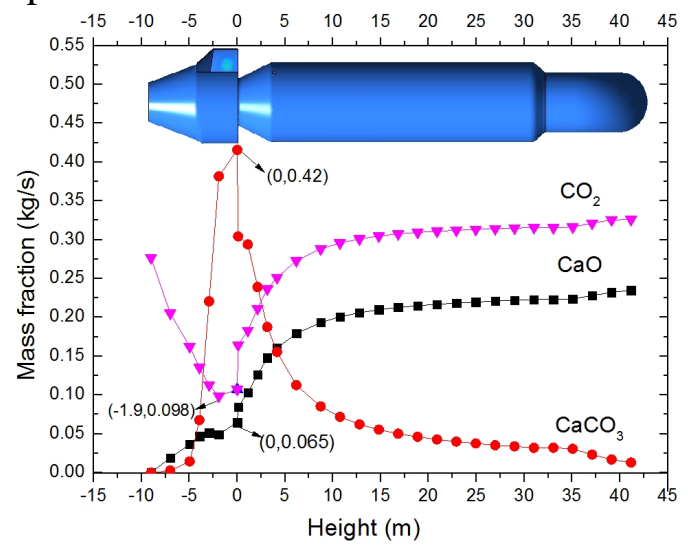

Fig. 8. Mass fraction of $\mathrm{CaCO}_{3}$ and $\mathrm{CaO}$ and $\mathrm{CO}_{2}$ with $\mathrm{CaCO}_{3}$ decomposition.

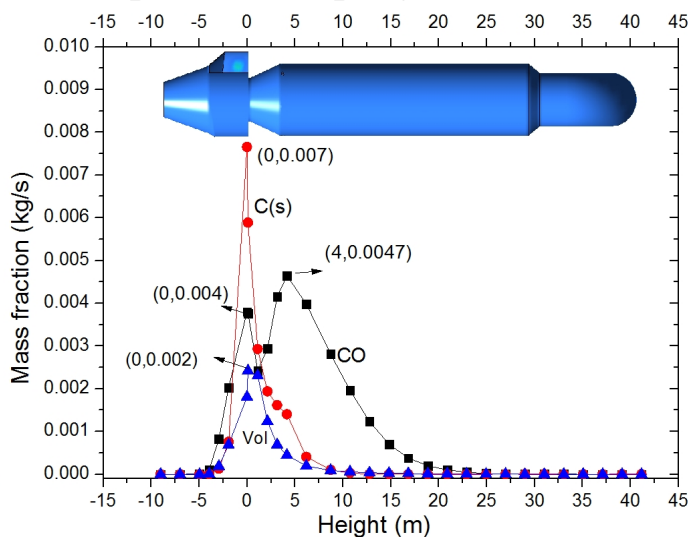

Fig.9. Mass fraction of $\mathrm{CO}$ and $\mathrm{C}(\mathrm{S})$ and $\mathrm{Vol}$ with $\mathrm{CaCO}_{3}$ decomposition.

Fig.8 shows the mass fraction of $\mathrm{CaCO}_{3}$ and $\mathrm{CaO}$ and $\mathrm{CO}_{2}$ in the precalciner on cross slices along $\mathrm{z}$ direction. Fig.9 shows the mass fraction of $\mathrm{CO}, \mathrm{C}(\mathrm{s})$ and $\mathrm{Vol}$ on cross slices along $\mathrm{z}$ direction.

It shows in fig. 8 that the concentration of $\mathrm{CaCO}_{3}$ increases gradually from the bottom smoke inlet to the height of $\mathrm{z}=0 \mathrm{~m}$. And the concentration of $\mathrm{CaCO}_{3}$ reaches a maximum at the height of $\mathrm{z}=0 \mathrm{~m}$. Then the concentration of $\mathrm{CaCO}_{3}$ decreases gradually with the increasing of $\mathrm{z}$ height. The concentration of $\mathrm{CO}_{2}$ in the smoke inlet is high and the value decreases gradually with the increasing of $\mathrm{z}$ height and reaches a minimum at the height of $\mathrm{z}=0 \mathrm{~m}$. Then the concentration of $\mathrm{CO}_{2}$ increases rapidly with the increasing of $\mathrm{z}$ height. The concentration of $\mathrm{CaO}$ increased rapidly firstly and then increased gradually.In fig. 9, the trend of the average mass fraction of $\mathrm{C}(\mathrm{s})$ and $\mathrm{Vol}$ are in accord with the $\mathrm{CaCO}_{3}$, reaches a maximum at the height of $\mathrm{z}=0 \mathrm{~m}$. The trend of the average mass fraction of $\mathrm{CO}$ is accord with the $\mathrm{C}(\mathrm{s})$, at the height of $\mathrm{z}=0 \mathrm{~m}$ reaches a maximum and then decreases gradually. However, at the height of $\mathrm{z}=1 \mathrm{~m}$, the concentration of $\mathrm{CO}$ reaches a minimum and then increases gradually and reaches a maximum at the height of $\mathrm{z}=4 \mathrm{~m}$. The concentration of $\mathrm{CaCO}_{3}, \mathrm{C}(\mathrm{s})$ and vol reaches a maximum at the height of $\mathrm{z}=0 \mathrm{~m}$. This is because both of the pulverized coal and the raw meals are injected into the precalciner at the height of $\mathrm{z}=0 \mathrm{~m}$ in different directions. With the gas-flow move upwards and downwards the concentration of $\mathrm{CaCO}_{3}, \mathrm{C}(\mathrm{s})$ and Vol decreases. On the one hand, it shows that the simulation of decomposition is in accord with the gas-solid flow. On the other hand, this phenomena shows materials have reacted in the process of moving upwards and downwards. The concentration of $\mathrm{CaO}$ is not zero in raw meal inlets, shows that part of $\mathrm{CaCO}_{3}$ decompose in the swirl chamber. With the upwards movement of gas-flow, the concentration of $\mathrm{CaO}$ increases gradually. Part of $\mathrm{CO}_{2}$ comes from the smoke inlet, so the concentration of $\mathrm{CO}_{2}$ is high in the smoke inlet and then decreases with the increased of inner diameter. At the height of $\mathrm{z}=-1.9 \mathrm{~m}$ the concentration of reached a minimum. Then with the $\mathrm{CaCO}_{3}$ decomposition, the concentration of $\mathrm{CO}_{2}$ increases rapidly. It shows that the $\mathrm{CaCO}_{3}$ decomposition are main at the height of $-9 \mathrm{~m}<\mathrm{z}<10 \mathrm{~m}$. And this is also the main combustion zone.

At the height of $z>20 m$, most of combustion and decomposition have been completed. Fig. 8 shows that the mass fraction of $\mathrm{CaCO}_{3}$ is only 0.01 at the height of $\mathrm{z}=40 \mathrm{~m}$, in other words the $\mathrm{CaCO}_{3}$ has decomposed completely. The post processing of the simulation data shows the decomposition rate is about $96.14 \%$, which is in accord with the actual decomposition rate $95 \%$. The average mass fraction 
of $\mathrm{CO}$ reached a maximum at the height of $\mathrm{z}=0 \mathrm{~m}$. This is because the pulverized coal was injected into the precalciner while the oxygen is not enough to support the complete combustion, part of pulverized coal incomplete combustion and format $\mathrm{CO}$. In the diverging pipe, the oxygen is enough, so part of $\mathrm{CO}$ is transformed into $\mathrm{CO}_{2}$. With the increasing of inner diameter, part of pulverized coal combusted incompletely and the concentration of $\mathrm{CO}$ reached peak at the height of $\mathrm{z}=4 \mathrm{~m}$. At the height of $\mathrm{z}=20 \mathrm{~m}$, nearly all the $\mathrm{CO}$ has been transformed to $\mathrm{CO}_{2}$.

Through the above qualitative and quantitative analysis, it shows the pulverized coal combustion and the $\mathrm{CaCO}_{3}$ decomposition is ideal, the structure of the precalciner is rational.

\section{Conclusions}

In this paper, the numerical simulation technique is utilized for a 5000t/d in-line precalciner with swirl chamber to analyze the characteristics of pulverized coal combustion and calcium carbonate decomposition. The results show that:

(1)The characteristic of gas-flow in swirl chamber precalciner was that gas rised spirally after being injected into the precalciner and the velocity in the center was lower.

(2)The particles moved with gas-flow after being injected into the precalciner vertically at $\mathrm{Z}=0 \mathrm{~m}$. And the pulverized coal burned mainly upper the swirl chamber, which could burn further in the diverging pipe with the movement of the gas-flow. The decomposition of calcium carbonate was also in the swirl chamber and the middle and lower part of the precalciner.

(3)The simulation result showed the burn-out ratio was about $100 \%$, the decomposition ratio of $\mathrm{CaCO}_{3}$ was about $96.14 \%$, which was agreement with the actual working conditions.

\section{Acknowledgements}

This work was financially supported by the National Natural Science Foundation of China (51502221).

\section{References}

[1] Jiamei Wang, Guoquan Xiao, Baoguo Ma: Journal of wuhan university of technology, 2006, 21 (4), 177-179. (In Chinese)

[2] Wenquan Tao,in: Numerical Heat Transer. 2nd edition, edtied by Xi' an Jiaotong University Press, Xi'an, Shanxi(2001). (In Chinese)

[3] Jianxi Li:Cement Technology, 2009,(1), 20-24. (In Chinese)

[4] B Wang, D.L. Xu, K.W.Chu, A.B.Yu: Applied mathematical modelling, 2006, 30(11): 1326-1342.

[5] Fidaros, D K, Baxevanou, C A, Dritselis, C D, et al. :Powder Technology, 2007, 171(2): 81-95.

[6] Giddings D, Eastw ick C N, Pickering S J. : Journal of Power and Energy, 2000, 214(3), 269-280.

[7] Mikulčić, H, von Berg, E, Vujanović, M, et al. :Chemical engineering science, 2012, 69(1): 607-615.

[8] Mikulčić, H, von Berg, E, Vujanović, M, et al.:Clean technology environment policy, 2013, 15: 489-499.

[9] Haitao Li, in:New dry process cement production technology and equipment. 1st edition, edited by Bei Jing: Chemistry Industry Press, Beijing(2006). (in Chinese) 